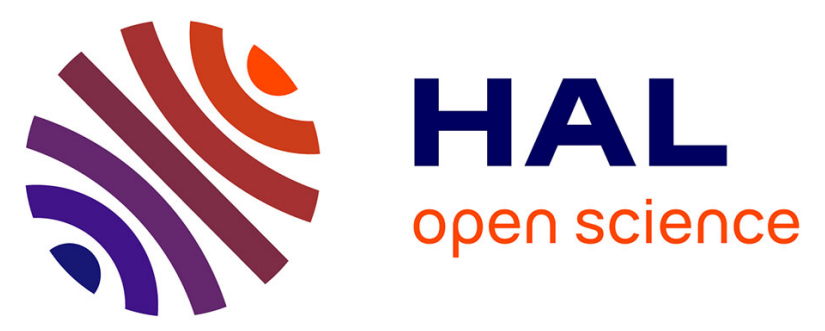

\title{
Using density management diagrams to assess crown fire potential in Pinus pinaster Ait. stands
}

\author{
Ibán Gómez-Vázquez, Paulo M. Fernandes, Manuel Arias-Rodil, Marcos
}

Barrio-Anta, Fernando Castedo-Dorado

\section{- To cite this version:}

Ibán Gómez-Vázquez, Paulo M. Fernandes, Manuel Arias-Rodil, Marcos Barrio-Anta, Fernando Castedo-Dorado. Using density management diagrams to assess crown fire potential in Pinus pinaster Ait. stands. Annals of Forest Science, 2014, 71 (4), pp.473 - 484. 10.1007/s13595-013-0350-4 . hal-01101758

\section{HAL Id: hal-01101758 \\ https://hal.science/hal-01101758}

Submitted on 9 Jan 2015

HAL is a multi-disciplinary open access archive for the deposit and dissemination of scientific research documents, whether they are published or not. The documents may come from teaching and research institutions in France or abroad, or from public or private research centers.
L'archive ouverte pluridisciplinaire HAL, est destinée au dépôt et à la diffusion de documents scientifiques de niveau recherche, publiés ou non, émanant des établissements d'enseignement et de recherche français ou étrangers, des laboratoires publics ou privés. 


\title{
Using density management diagrams to assess crown fire potential in Pinus pinaster Ait. stands
}

\author{
Ibán Gómez-Vázquez • Paulo M. Fernandes • \\ Manuel Arias-Rodil • Marcos Barrio-Anta • \\ Fernando Castedo-Dorado
}

Received: 22 July 2013 / Accepted: 25 November 2013 /Published online: 24 December 2013

(C) INRA and Springer-Verlag France 2013

\begin{abstract}
- Context Density management diagrams (DMDs) are useful for designing, displaying and evaluating alternative density management regimes for a given stand-level management objective. The inclusion of variables related to crown fire potential within DMDs has not previously been considered.

- Aims The aim of this study was to include isolines of variables related to crown fire initiation and spread in DMDs to enable identification of stand structures associated with different types of wildfire.
\end{abstract}

\section{Handling Editor: Eric Rigolot}

Contribution of the co-authors Iban Gómez-Vázquez collected some of the biometrical data, analysed the data and wrote the manuscript. Paulo M. Fernandes provided technical assistance in fire behaviour simulations and supervised the writing of the manuscript.

Manuel Arias-Rodil developed the R script for constructing the tailormade DMDs.

Marcos Barrio-Anta provided some of the experimental data and revised the text.

Fernando Castedo-Dorado coordinated the research project and supervised the study.

Electronic supplementary material The online version of this article (doi:10.1007/s13595-013-0350-4) contains supplementary material, which is available to authorized users.

I. Gómez-Vázquez • M. Arias-Rodil

Departamento de Ingeniería Agroforestal, Escuela Politécnica

Superior, Universidad de Santiago de Compostela, R/ Benigno Ledo,

Campus Universitario, 27002 Lugo, Spain

I. Gómez-Vázquez

e-mail: iban.gomez.vazquez@gmail.es

M. Arias-Rodil

e-mail: m.arias1987@gmail.com

\section{P. M. Fernandes}

Centro de Investigação e de Tecnologias Agro-Ambientais e

Biológicas (CITAB), Universidade de Trás-os-Montes e Alto Douro, Apartado 1013, 5001-801 Vila Real, Portugal

e-mail: pfern@utad.pt
- Methods Biometric and fuel data from maritime pine (Pinus pinaster Ait.) stands in NW Spain were used to construct DMDs. Different surface and crown fire behaviour models were used together to estimate crown fire potential.

- Results The crown fire potential varied greatly throughout development of the maritime pine stands. Low stands were more prone to crowning. The type of crown fire was mainly determined by stand density.

- Conclusion The DMDs developed can be used to identify relationships between stand structure and crown fire potential,

M. Barrio-Anta

Departamento de Biología de Organismos y Sistemas, Escuela Politécnica de Mieres, Universidad de Oviedo, C/ Gonzalo Gutiérrez Quirós, 33600 Mieres, Asturias, Spain e-mail: barriomarcos@uniovi.es

F. Castedo-Dorado $(\bowtie)$

Departamento de Ingeniería y Ciencias Agrarias, Escuela Superior y

Técnica de Ingeniería Agraria, Universidad de León, Avda. de

Astorga s/n, 24400 Ponferrada, León, Spain

e-mail: fcasd@unileon.es 
thus enabling the design of thinning schedules aimed at reducing the likelihood of crowning.

Keywords Stand management $\cdot$ Surface fire intensity $\cdot$ Forest structure $\cdot$ Crowning potential $\cdot$ Maritime pine

\section{Introduction}

Stand density management is the process of controlling the level of growing stock through initial spacing and (or) subsequent thinnings to achieve specific management objectives (Newton 2012). Given the multitude of treatment options available, stand density management is a complex process, which is facilitated by decision-making support tools such as density management diagrams (DMDs). DMDs are graphical models that reflect the relationships between yield and density at all stages of stand development in even-aged stands, and they are useful for designing, displaying and evaluating alternative density management regimes (e.g. Newton 2012; Vacchiano et al. 2013).

Silviculturists are frequently called on to design stand structures for an increasingly expanding array of objectives. Currently, one of the main objectives of stand management in Mediterranean areas of Europe is the mitigation of crown fire hazard. Crown fires, which are fast and intense, are hence difficult and dangerous to suppress and cause severe economic damage and ecological disruption (Alexander and Cruz 2011). Assessing the risk of crown fire initiation and spread is therefore a key element in fire mitigation and suppression planning (Scott and Reinhardt 2001).

Effective silvicultural strategies for reducing the likelihood and severity of crown fires are well established and include reducing surface fuels, increasing canopy base height and reducing canopy bulk density (e.g. Agee and Skinner 2005; Graham et al. 2004). When present, shrubs are clearly involved in the initiation of crown fires as they increase surface fire intensity and decrease the gap between surface and canopy fuel layers. This is quite apparent in the northwestern Iberian Peninsula, where understory shrubs often dominate the surface fuel complex and surface fuel loads are among the highest in pine stands in temperate climates (e.g. Fernandes et al. 2009). Canopy base height and canopy bulk density are key canopy fuel complex variables because of their important role in crown fire initiation and spread (e.g. Alexander and Cruz 2011). Canopy base height $(C B H)$ is a measure of the proximity of canopy fuels to surface fuels and strongly influences the likelihood of crown fire initiation, whereas canopy bulk density $(C B D)$ describes the amount of available fuel within a unit volume of the canopy and is a key variable in discriminating the type of crown fire (Van Wagner 1977) and its rate of spread (Cruz et al. 2005).
Maritime pine is known for its flammability and susceptibility to wildfire in southwestern Europe (Fernandes and Rigolot 2007). In stands of this species, both surface and canopy fuel variables (surface fuel loads and heights, $C B H$ and $C B D$ ) depend to a certain degree on stand structure and are therefore responsive to stand density management (Castedo-Dorado et al. 2012; Gómez-Vázquez et al. 2013). Previous studies have addressed the relationship between stand structure and fire behaviour and crowning hazard in this species (e.g. Fernandes 2009), but no quantitative methods are available to assess the expected fire behaviour associated with silvicultural schedules. The inclusion of information on crown fire-related variables in DMDs would enable crown fire potential to be assessed throughout stand development, thus enabling the design of appropriate density management alternatives.

The objectives of the present study were as follows: (a) to develop a basic DMD for $P$. pinaster stands in NW Spain to estimate yield-related variables and (b) to include variables related to crown fire initiation and spread in the basic DMD to enable identification of the stand structures associated with different types of wildfire. The usefulness of DMDs for assessing the effects of stand structure on crown fire potential and for designing stand density schedules is also discussed.

\section{Material and methods}

\subsection{Data}

The data used to develop the DMDs were obtained from two sources. The first comprised 82 plots located in pure (more than $90 \%$ of total stand basal area) even-aged stands of maritime pine in NW Spain (Galicia and Asturias). The plots were mainly located in young stands throughout the distribution area of the species in NW Spain. Plot size ranged from 400 to $3,000 \mathrm{~m}^{2}$. The diameter at breast height $(d$, in centimetres) and height ( $h$, in metres) were measured in each tree in each sample plot. Individual-tree volume was estimated using the volume equations of Diéguez-Aranda et al. (2009).

The second source of data was the fourth Spanish National Forest Inventory (SNFI) for the region of Galicia (MARM 2011). The SNFI is a systematic sample of permanent plots distributed on a 1-km square grid, in which, besides recording $d$ and $h$, the percent overstory canopy cover $(C c)$ was visually assessed. We selected 837 plots in which maritime pine was dominant (more than $90 \%$ of total stand basal area). We only used the SNFI data to fit an equation to estimate canopy cover and not to construct the basic DMD because we considered the high-quality data from the 82 permanent plots sufficient for this purpose.

For both data sources, we calculated the following stand variables for each plot: number of trees per hectare $(N)$; stand 
basal area $(G$, in square metres per hectare); quadratic mean diameter $\left(d_{g}\right.$, in centimetres); average stand height $\left(H_{m}\right.$, in metres); dominant height $\left(H_{0}\right.$, in metres) defined as the mean height of the 100 largest-diameter trees per hectare; relative spacing index $\left[R S(\%)=10,000 /\left(H_{0} \cdot N^{0.5}\right)\right.$, i.e. the ratio, expressed as a percentage, between the average distance among trees and $H_{0}$ ], assuming square spacing of the trees; and stand volume ( $V$, in cubic metres per hectare). We determined stand age $(t)$ from the plantation date. Summary statistics (minimum, maximum and mean values and standard deviations) of these stand variables are listed in Table 1.

\subsection{Construction of the basic DMD}

The basic DMD includes a system of two equations and the $R S$ as components (Barrio-Anta and ÁlvarezGonzález 2005). Relative spacing index is useful in stand density management because it is independent of site quality and stand age except for very young stands, and dominant height growth is one of the best criteria for establishing thinning intervals. The first equation in the system relates quadratic mean diameter to stand density and dominant height (Eq. (1)), and the second equation relates stand volume to quadratic mean diameter, stand density and dominant height (Eq. (2)):

$d_{g}=\beta_{0} \cdot N^{\beta_{1}} \cdot H_{0}^{\beta_{2}}$

$V=\beta_{3} \cdot d_{g}^{\beta_{4}} \cdot H_{0}^{\beta_{5}} \cdot N^{\beta_{6}}$

where all the stand variables were previously defined and $\beta_{i}$ $(i=0,1, \ldots, 6)$ are the regression coefficients to be estimated. Equations (1) and (2) together define a structurally simultaneous system of equations where $N$ and $H_{0}$ are the exogenous variables and $d_{g}$ is an endogenous instrumental variable. Since the error components of the variables on the left-hand side and the right-hand side are correlated, we applied the full information maximum likelihood technique, with the SAS/ ETS ${ }^{\circledR}$ PROC MODEL procedure (SAS Institute Inc. 2009), to fit both equations simultaneously.

The final step in constructing the basic DMD consists of plotting the isolines for the growing stock (expressed by the $R S$ ) and for the stand variables included in the system of equations $\left(d_{g}\right.$ and $V$ ). Although different methods have been proposed for constructing DMDs, in the approach presented here, dominant height was represented on the $x$-axis and the number of trees per hectare (in logarithmic scale) on the $y$ axis, and isolines for $R S, d_{g}$ and $V$ were superimposed on the bivariate graph. Isolines for $d_{g}$ were plotted in the DMDs using constant values for $d_{g}$ and solving Eq. (1) for $N$, whereas the isolines for $V$ were plotted by solving $d_{g}$ in Eq. (2) with Eq. (1), assuming constant values for $V$ and solving for $N$. For more details on plotting the isolines, see Barrio-Anta and Álvarez-González (2005) or Castedo-Dorado et al. (2009).

\subsection{Assessment of crown fire potential}

To assess crown fire potential, we combined the following models: the modified version (Fernandes 2014) of the surface fire behaviour model of Fernandes et al. (2009), empirically developed from 94 experimental fires in $P$. pinaster stands in Portugal; the Byram's (1959) fireline intensity model; the Van Wagner's (1977) crown fire initiation model and criterion for active crowning (CAC), and the crown fire rate of spread model of Cruz et al. (2005). The semiempirical crown fire initiation model of Van Wagner (1977), although not extensively evaluated, is widely accepted by the fire science community. Moreover, this model has been implemented in most US fire modelling systems (BehavePlus, FARSITE, FlamMap), which are used extensively elsewhere. The CAC and the model by
Table 1 Summary statistics of the biometric data set used to construct the DMDs
$N$ number of stems per hectare, $G$ stand basal area, $d_{g}$ quadratic mean diameter, $H_{m}$ average stand height, $H_{0}$ dominant height, $V$ total stand volume, $t$ stand age, $N_{\text {dead }}$ number of dead stems per hectare, $C c$ overstory canopy cover

\begin{tabular}{|c|c|c|c|c|c|c|c|c|}
\hline \multirow[b]{2}{*}{ Stand variable } & \multicolumn{4}{|c|}{ Permanent plots $(n=82)$} & \multicolumn{4}{|c|}{ SNFI plots $(n=837)$} \\
\hline & Mean & Max & Min & $\mathrm{SD}$ & Mean & $\operatorname{Max}$ & Min & SD \\
\hline$N\left(\right.$ stems $\left.\mathrm{ha}^{-1}\right)$ & 1,346 & 2,440 & 400 & 417 & 632 & 3,724 & 5 & 543 \\
\hline$G\left(\mathrm{~m}^{2} \mathrm{ha}^{-1}\right)$ & 30.5 & 68.8 & 7.80 & 10.8 & 22.6 & 86.2 & 0.436 & 15.2 \\
\hline$d_{g}(\mathrm{~cm})$ & 17.1 & 24.1 & 10.4 & 3.40 & 23.4 & 56.7 & 7.50 & 8.60 \\
\hline$H_{m}(\mathrm{~m})$ & 10.6 & 18.9 & 4.71 & 2.72 & 12.7 & 27.2 & 2.86 & 4.43 \\
\hline$H_{0}(\mathrm{~m})$ & 12.2 & 20.9 & 5.43 & 3.14 & 15.8 & 28.9 & 3.34 & 5.67 \\
\hline$R S(\%)$ & 24.6 & 60.6 & 12.6 & 8.00 & 47.0 & 295.4 & 7.81 & 51.0 \\
\hline$V\left(\mathrm{~m}^{3} \mathrm{ha}^{-1}\right)$ & 152.6 & 456.3 & 16.4 & 85.1 & - & - & - & - \\
\hline$t$ (years) & 18.7 & 32 & 8 & 4.8 & - & - & - & - \\
\hline$N_{\text {dead }}\left(\right.$ stems ha $\left.{ }^{-1}\right)$ & 49.9 & 140 & 0 & 54.7 & - & - & - & - \\
\hline$C c(\%)$ & - & - & - & - & 59.1 & 100 & 5.00 & 21.7 \\
\hline
\end{tabular}


Cruz et al. (2005) have been successfully evaluated (Alexander and Cruz 2006) and have been used in European crown-fire modelling studies (e.g. Dimitrakopoulos et al. 2007; Fernández-Alonso et al. 2013). We chose this option as the modelling solution because of the compatibility between models.

Byram (1959) defined fire intensity $\left(I_{\mathrm{B}}\right)$ as the rate of heat released from a linear segment of the fire front (in kilowatts per metre):

$I_{\mathrm{B}}=R \cdot W \cdot H$

where $R=$ rate of fire spread (in metres per second), $W=$ amount of fuel consumed in the flaming front (in kilograms per square metre) and $H=$ net heat of combustion or heat yield (in kilojoules per kilogram), which can be fixed to a nominal value of $18,000 \mathrm{~kJ} \mathrm{~kg}^{-1}$ (Alexander 1982).

We calculated the rate of fire spread $R$ (in metres per minute) for Eq. (3) by modifying the equation proposed by Fernandes et al. (2009) for fitting wildfire data (Fernandes 2014):

$R=2.040 \cdot U^{0.707} \cdot \exp (0.062 \cdot S-0.039 \cdot M S) \cdot F D^{0.188}$

where $U=$ in-stand wind speed at $1.7-\mathrm{m}$ above ground (in kilometres per hour), $S=$ terrain slope (in degrees), $M S=$ moisture content of fine dead surface fuels (in percent) and $F D=$ surface fuel depth (in metres).

We obtained $U$ by adjusting open wind speed at $10 \mathrm{~m}$ above ground level (see below), and we fixed $S$ and $M S$ at $0^{\circ}$ and $8 \%$, respectively. These values might be seen as rather conservative, but more extreme fire environments would be outside the ranges of experimental conditions considered by Cruz et al. (2005). Moreover, more severe burning conditions are expected to decrease the relative effect of fuel structure on fire behaviour.

We estimated surface fuel depth $(F D)$ as the sum of understory vegetation (shrubs) and litter (L-layer) depths (Fernandes et al. 2009). We estimated shrub depth from the quantile regression models of Castedo-Dorado et al. (2012), which relates shrub height ( $S H$, in metres) to stand basal area ( $G$, in square metres per hectare). We considered two scenarios of shrub height (given by the 50th and 95th quantile models):

50th : $S H=0.8358-0.00336 \cdot G ; \quad 95$ th $: S H=1.96-0.0111 \cdot G$

As there are no equations available for estimating L-layer depth from stand variables, we assumed a well-developed litter layer 3-cm deep (Fernandes et al. 2002). Accordingly, we computed $F D$ for all plots as $S H+0.03$.

We estimated fuel consumption of the litter and understory shrub layers from $M s$ ( $8 \%$ ), using the model proposed by
Fernandes and Loureiro (2013), as 99 and $92 \%$, respectively. Therefore, we calculated $W$ in Eq. (3) as follows:

$W=0.99 \cdot W l+0.92 \cdot S W a$

We estimated $W l$ (in kilograms per square metre) by using the following equation (Fernandes et al. 2002):

$W l=0.1108 \cdot G^{0.473} \cdot(1-\exp (-0.871 \cdot t))$

where $G=$ stand basal area (in square metres per hectare) and $t=$ stand age (in the absence of fuel treatments) or time since the last prescribed fire. We assumed a steady-state accumulation of L-layer litter, consistent with a $3-\mathrm{cm}$ depth and set $t$ to 4 years.

As with $S H$, we estimated the available shrub fuel load $\mathrm{SWa}$ (in kilograms per square metre) from the 50th and 97.5th quantile regression models developed by Castedo-Dorado et al. (2012):

50th : $S W a=1.407-0.01364 \cdot G ; \quad 97.5$ th $: S W a=3.561-0.02507 \cdot G$

Vertical fire spread occurs in a conifer stand when surface fire intensity exceeds a certain threshold for crown combustion $\left(I_{0}\right)$, as per Van Wagner (1977):

$I_{0}=[0.01 \cdot C B H \cdot(460+25.9 \cdot F M C)]^{1.5}$

where $I_{0}$ is the critical fire intensity (in kilowatts per metre); $F M C$ is the tree foliage moisture content (in percent), fixed at $100 \%$; and $C B H$ is the canopy base height (in metres), estimated from the average stand height $\left(H_{m}\right.$, in metres) (Gómez-Vázquez et al. 2013):

$C B H=0.1213 \cdot H_{m}^{1.596}$

If $I_{\mathrm{B}}>I_{0}$, a crown fire is likely to occur; otherwise, a surface fire will take place. In the former case, we used the CAC (Van Wagner 1977) to assess the type of crown fire (active or passive). CAC is the ratio of the predicted crown fire rate of spread $\left(R_{\mathrm{c}}\right)$ and the critical minimum rate of spread $\left(R_{0}\right)$ for active crowning. We estimated $R_{\mathrm{c}}$ (in metres per minute) using the model of Cruz et al. (2005) (Eq. (11)), whereas we calculated $R_{0}$ (in metres per minute) according to Van Wagner (1977) (Eq. (12)):

$R_{\mathrm{c}}=11.02 \cdot U_{10}^{0.9} \cdot C B D^{0.19} \cdot \exp (-0.17 \cdot M s)$

$R_{0}=3 / C B D$

where $U_{10}=10$-m open wind speed (in kilometres per hour), $M s=8 \%$ and $C B D=$ canopy bulk density (in kilograms per cubic metre), estimated from $G$ (in square metres per hectare) 
and $N$ (trees per hectare) with the following equation (Gómez-Vázquez et al. 2013):

$C B D=0.004207 \cdot G^{0.7333} \cdot N^{0.1751}$

We set $U_{10}$ to $30 \mathrm{~km} \mathrm{~h}^{-1}$ to represent a high fire weather scenario (Fernandes 2009; Fernández-Alonso et al. 2013). $U_{10}$ will lead to different $U$ values, depending on stand structure. We used the approach of Finney (2004), based on that proposed by Albini and Baughman (1979), to adjust $U_{10}$ to $U$ :

$U=\frac{U_{10}}{1.15} \cdot \frac{0.555}{\sqrt{(C c / 100) \cdot(\pi / 12) \cdot 3.28 \cdot H_{0}}}$

where $U=$ surface wind speed (in kilometres per hour), $U_{10}=10-\mathrm{m}$ open wind speed (in kilometres per hour), $C c=$ overstory canopy cover (in percent) and $H_{0}=$ stand dominant height (in metres), which approximately defines stand height sensu Finney (2004).

Assessment of crown fire potential consisted of two stages. In the first stage, we used Eqs. (3) and (10) to assess surface to crown fire transition. For constant values of $F M C, S$ and $M s$, fire intensities depend only on the stand variables $H_{m}$ (indirectly through Eq. (9)), $G, C c$ and $H_{0}$ (indirectly through Eq. (3)). As $G$ $=\pi / 40,000 \cdot d_{g}{ }^{2} \cdot N$ and $d_{g}$, in turn, is a function of $N$ and $H_{0}$ (Eq. (1)), $C c$ and $H_{m}$ are the only unknown stand variables for a given combination of $N$ and $H_{0}$. We therefore used the MODEL procedure of SAS/ETS ${ }^{\circledR}$ (SAS Institute Inc. 2009) to develop empirical regression models relating $C c$ and $H_{m}$ to other stand variables that are easy to obtain in the field and to represent in the DMD $\left(R S, G, N, d_{g}, H_{0}\right)$.

In the second phase, we used Eqs. (11) and (12) to assess the type of crown fire expected. For constant $U_{10}$ and $F M C$ values, both $R_{\mathrm{c}}$ and $R_{0}$ depend, ultimately, only on the stand variables $G$ and $N$. Therefore, the combination of $N$ and $H_{0}$ where $\mathrm{CAC}=1$ (i.e. where isolines $R_{\mathrm{c}}$ and $R_{0}$ isolines meet) can be delineated in the DMD. The graphical description of the interrelationships between the variables and equations used in the simulation is shown in Fig. 1.

\section{Results}

Equations (15) and (16) show the parameter estimates resulting from the fitted Eqs. (1) and (2):

$d_{g}=29.35 \cdot N^{-0.2757} \cdot H_{0}^{0.5765} ; R^{2}=0.773 ; \mathrm{RMSE}=1.62 \mathrm{~cm}$
$V=0.00004982 \cdot d_{g}^{1.883} \cdot H_{0}^{1.066} \cdot N^{0.9540} ; R^{2}=0.992 ; \mathrm{RMSE}=7.20 \mathrm{~m}^{3} \mathrm{ha}^{-1}$

According to the goodness-of-fit statistics, both equations performed well and explained more than 77 and $99 \%$ of the total variability in $d_{g}$ and $V$, respectively. All parameter estimates were significant at the $1 \%$ level. Examination of residuals revealed that all regression models were unbiased with respect to the independent variables.

A basic DMD was constructed by superimposing the expected size-density trajectories (i.e. the values of $R S$ ), the isolines for $d_{g}$ and the isolines for $V$ on the bivariate graph (Fig. 2). For more details of the procedure for representing these variables, see Barrio-Anta and Álvarez-González (2005) or Castedo-Dorado et al. (2009). The range of values represented by the axes and the isolines were similar to the range of values included in the data used to construct the diagram, although open and low, and closed and tall stands (lower-left and upper-right corners in DMD of Fig. 2, respectively) are not well represented.

To assess crown fire potential, we first developed equations for estimating $H_{m}$ and $C c$. The following linear equation was the most adequate for modelling $H_{m}$ data:

$H_{m}=-0.3680+0.8992 \cdot H_{0} ; R^{2}=0.968 ; \mathrm{RMSE}=0.477 \mathrm{~m}$

The following allometric model performed best in modelling $C c$ variation:

$C c=-120.1 \cdot G^{0.1057} \cdot R S^{-0.2979} ; R^{2}=0.555 ; \mathrm{RMSE}=14.5 \%$

Although Eq. (18) did not explain a high percentage of the variability, it provided a random pattern of residuals around zero and the signs of the parameter estimates are logical ( $C c$ increases when $G$ increases and $R S$ decreases).

To assess surface to crown fire transition, we attempted to develop an explicit formulation of $N$ as a function of $I_{\mathrm{B}}$ (Eq. (3)) and $H_{0}$. However, this was not possible and we had to use iterative procedures to solve $N$ for different combinations of $I_{\mathrm{B}}$ and $H_{0}$. These values were subsequently represented as $I_{\mathrm{B}}$ isolines in the DMD.

The $I_{0}$ isolines were drawn as vertical lines because $I_{0}$ does not depend on stand density (i.e. for the same $H_{0}, I_{0}$ is constant for the range of $N$ ): 
$H_{0}=\left[\left(\frac{I_{0}^{0.6667}}{31.97}\right)^{0.6266}+0.3660\right] / 0.9049$

To assess the type of crown fire that will develop if $I_{\mathrm{B}}>I_{0}$, we obtained the $C B D$ values that lead to $R_{\mathrm{c}}=R_{0}$ (i.e. the isoline that outlines the boundaries between active and passive crown fires) by equalling Eqs. (10) and (11) and solving for $N$ :

$N=\left(\frac{\left(1 /\left(3.367 \cdot U_{10}^{0.9} \cdot \exp (-0.17 \cdot M s)\right)\right)^{0.8403}}{0.0005838 \cdot H_{0}^{0.8449}}\right)^{1.984}$

For comparative purposes, we also included $C B D$ information in the DMD. To represent the isolines for $C B D$, we solved Eq. (12) for $N$ through a range of $H_{0}$ by setting $C B D$ constant:

$N=\left(\frac{C B D}{0.0005838 \cdot H_{0}^{0.8449}}\right)^{1.984}$

\section{Discussion}

\subsection{Basic DMD}

The basic DMD developed (Fig. 2) enables optimization of the trade-off between maximizing individual tree size and stand yield. Any proposed management regime can be included in the DMD as a series of horizontal lines (assuming no mortality) and vertical lines representing thinning segments. The rapidity with which the stand moves along horizontal lines depends on the site index, i.e. on the change in dominant height over time. The DMD did not include a density-dependent mortality model because there is no such model available at present (Diéguez-Aranda et al. 2009, p. 135). Moreover, we were not able to develop this type of model because of the very low or null natural mortality observed in most experimental plots (see Table 1). Therefore, we could not determine the empirical upper limit of growing stock (characterized in this study by $R S$ ) for which competition-induced mortality occurs. This may be due to the relatively narrow range of stem densities in the maritime pine stands in the region (most of which are planted) and to the silvicultural practices carried out (respacement and thinning). The basic DMD presented here differ from those developed for North American conifer stands, in which self-thinning is usually the main driver of stand development and the development of DMDs is underlain by the relationship between mean tree size (or per unit area yield) and density at which density-dependent mortality occurs (e.g. Newton 2012).

Nevertheless, the absence of a mortality model (hence the consideration of coarse woody debris as another component of the surface fuel complex) is not expected to have a great effect on assessment of the crown fire risk potential because large woody fuels have little influence on surface fire spread and intensity.

To enable the DMD to be used to assess crown fire initiation and the expected type of crown fire, we used the 50th and the 95th-97.5th regression quantile models of the surface fuel variables $S H$ and $S W a$ (Figs. 3 and 4, respectively) assuming relatively severe burning conditions. For these conditions, the fireline intensity of crown fires in maritime pine stands can vary in the $4,000-40,000-\mathrm{kW} \mathrm{m}^{-1}$ range, with a fireline intensity $>10,000 \mathrm{~kW} \mathrm{~m}^{-1}$ typically corresponding to active crown fire spread (Palheiro et al. 2006).

We include an R script (R Development Core Team 2011) as an Online Resource for constructing tailor-made DMDs that include the fuel and weather conditions of interest to the final users. Variables that can be changed include surface fine fuel moisture $(M S)$, foliar moisture content $(F M C)$, the 10-m wind speed $\left(U_{10}\right)$, and surface fuel heights and loads $(\mathrm{SH}$ and $S W a$ ), which can be estimated from the corresponding 50th, 75th and 95th-97.5th quantile regression models (CastedoDorado et al. 2012).

\subsection{Assessment of crown fire potential}

The isolines for assessing crown fire potential in the DMDs suggest an obvious variation in crown fire hazard throughout the development of maritime pine stands. According to Figs. 3 and 4 , crowning is possible until the $I_{0}$ and $I_{\mathrm{B}}$ isolines cross, i.e. until $H_{0}$ reaches 10.5 or $14 \mathrm{~m}$ (depending on the quantile regression model used for estimating $\mathrm{SH}$ and $\mathrm{SWa}$ ); only surface fires are expected when $H_{0}$ exceeds these values. This result is explained because low $I_{\mathrm{B}}$ and high $I_{0}$ simultaneously occur in tall stands. The low $I_{\mathrm{B}}$ is due to the reduced surface wind speed (i.e. low wind adjustment factor) and, to a lesser extent, to the overstory effect in controlling understory development. The high values of the critical fireline intensity are primarily explained by the strong correlation between $I_{0}$ and $H_{0}$ (see Eqs. $(9,10$ and 17)). Stand density does not influence $I_{0}$ estimates because $C B H$ depends on stand height only (Eq. (10)), which in turn is mainly explained by the effective self-pruning in maritime pine, even at low stocking levels (e.g. Fernandes and Rigolot 2007). However, it is recognized that the absence of influence of stand density on $C B H$ may also be partially masked because of the relatively narrow range of 


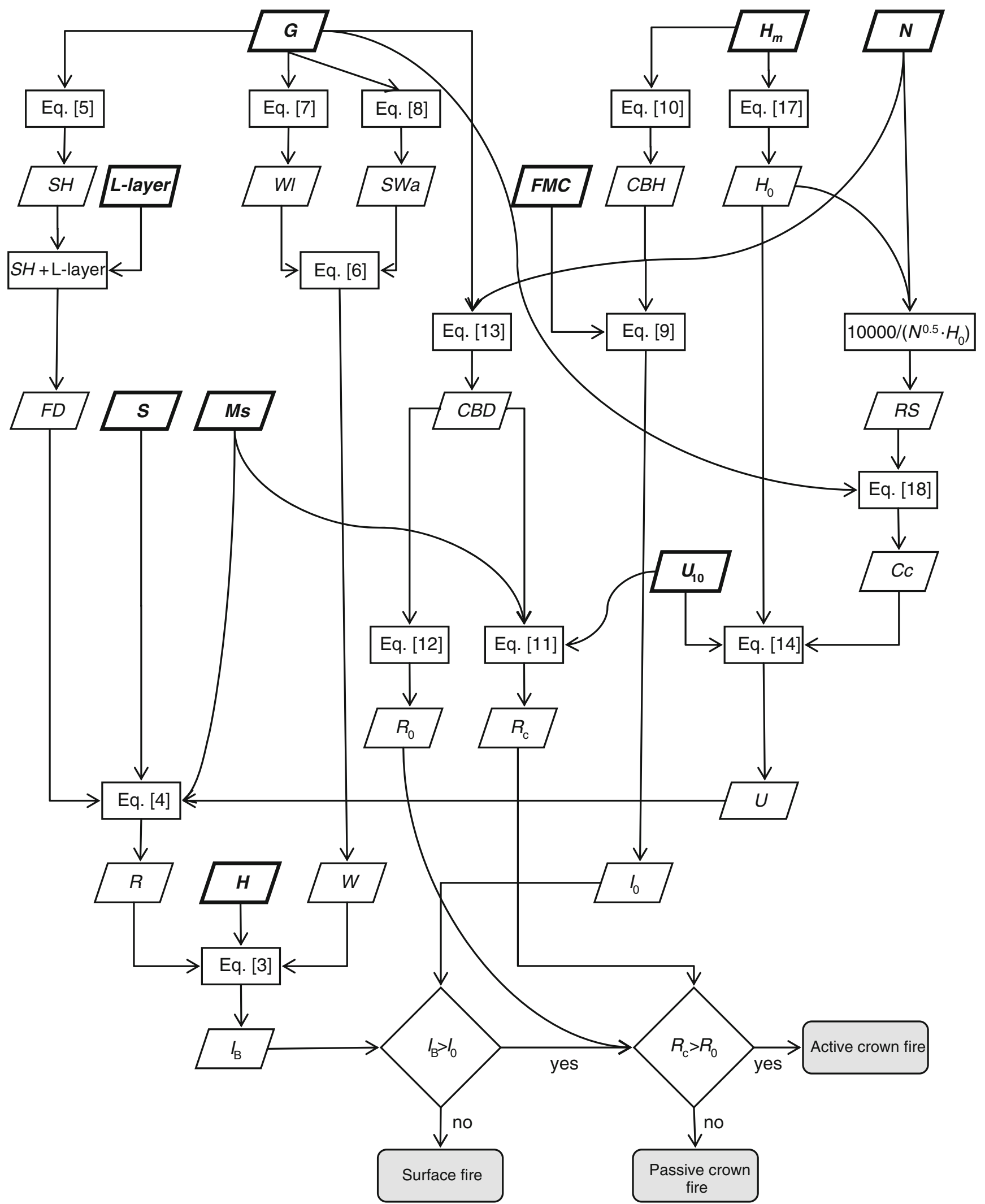

Fig. 1 Diagram showing the interrelationships among the variables and equations used in the simulation. Variables showed in bold are the inputs for the simulations 


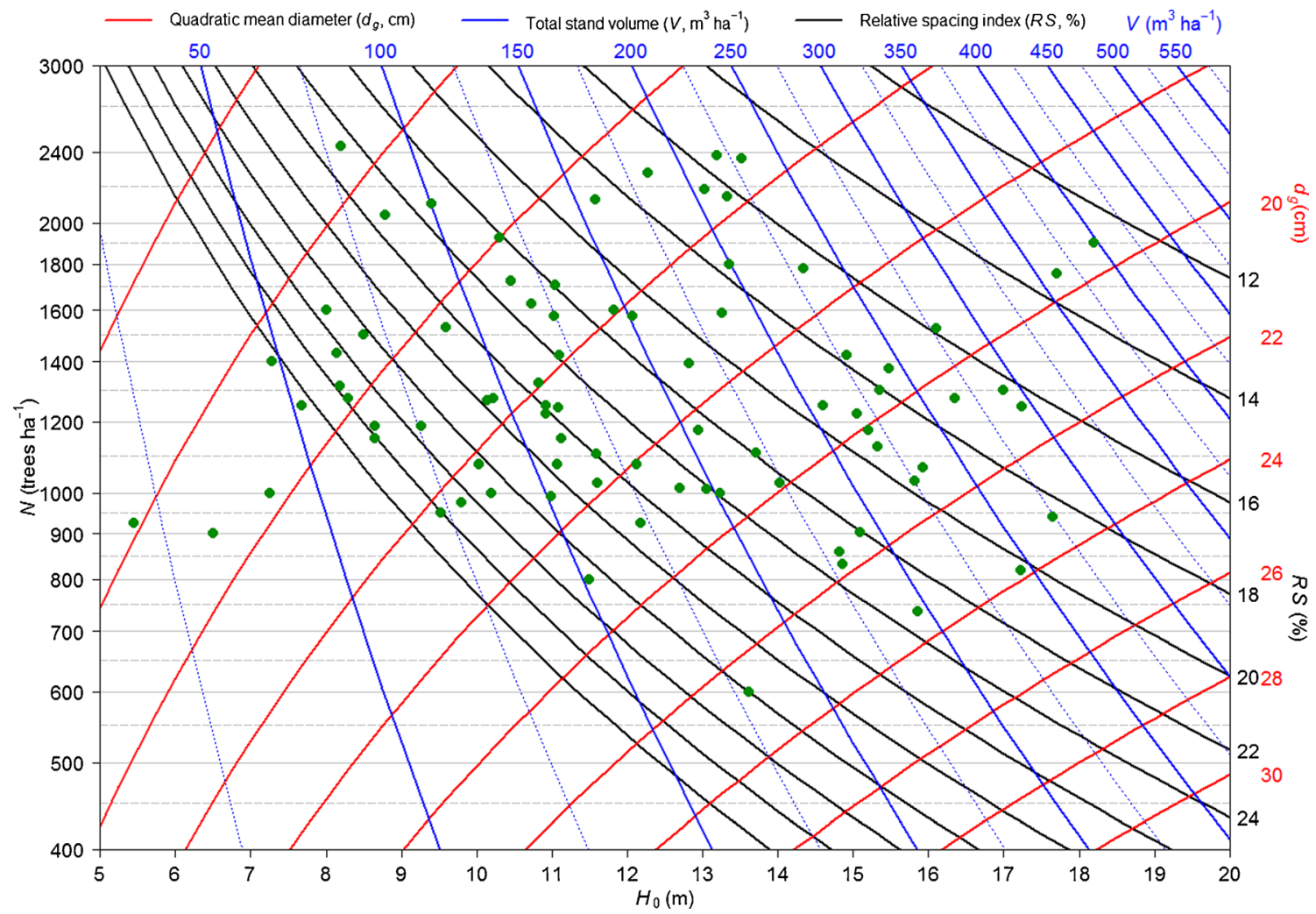

Fig. 2 Basic DMD for maritime pine stands in NW Spain with isolines for quadratic mean diameter $\left(d_{g}\right)$, total stand volume $(V)$ and relative spacing index $(R S)$. Points identify sampled plots used for model development

observed stand densities (see Table 1 for the database used in this article).

Empirical evidence shows that crown fires in maritime pine stands are more common in low (young) stands. For example, Jiménez et al. (2013) observed active crown fires in three stands with $H_{m}$ lower than $11.1 \mathrm{~m}$ and well-developed shrub stratum. In an experimental fire, Fernandes et al. (2004) also found crown fire activity in two plots with $H_{m}<9.1 \mathrm{~m}$ and high surface fuel loads. Although these specific case studies are not conclusive because fuel, topographic and meteorological conditions are different from those considered in the simulations, empirical evidence that mature (tall) stands are usually more resistant to fire than young (low) stands is abundant for other species (e.g. Pollet and Omi 2002; Alvarez et al. 2012).

For stand dominant heights lower than $10.5 \mathrm{~m}$ (Fig. 3) or $14 \mathrm{~m}$ (Fig. 4) in $H_{0}$, crowning is expected in both open and closed stands. The high $I_{\mathrm{B}}$ expected for low stands is explained by higher surface wind speed concurrent with the absence of shrub control through overstory canopy cover, leading to a very flammable surface fuel complex (Pollet and Omi 2002). In addition, early stages of maritime pine stands are more likely to experience crown fire due to their low mean height and low $C B H$, hence low $I_{0}$ (Fernandes and Rigolot 2007).

\subsection{Assessment of crown fire type}

The type of crown fire depends on both stand density and dominant height. For the simulated conditions, active crown fire occurs in stand structures generating $C B D$ higher than $0.08 \mathrm{~kg} \mathrm{~m}^{-3}$. This value is similar to the $0.1-\mathrm{kg} \mathrm{m}^{-3}$ threshold for active crowning empirically deduced by Agee (1996) and subsequently confirmed by Cruz et al. (2005). Passive crown fire will occur below the $0.08 C B D$ isoline, which is roughly defined by low $G$ values (ranging between 10 and $14 \mathrm{~m}^{2} \mathrm{ha}^{-1}$ ). Similar results have been reported for other conifer species, by Cruz et al. (2005) and Van Wagner (1977): silvicultural regimes that maintain denser stands (i.e. higher $G$ ) will sustain faster-spreading, higher-intensity fires if the combination of $C B H$ and surface fire intensity results in crowning.

Although in stands taller than $10.5 \mathrm{~m}$ (Fig. 3) or $14 \mathrm{~m}$ (Fig. 4) $C B D$ is always greater than the $0.1-\mathrm{kg} \mathrm{m}^{-3}$ nominal threshold, the elevated crown base height hinders crown fire development. Hence, a more intense surface fire would be required to reach the higher critical fire intensity implied by higher $C B H$. Scott and Reinhardt (2001) stated that in such situations, an active crown fire might spread through the stand if initiated in an adjacent stand; however, Alexander and Cruz (2011) dismiss this as an artefact of the Scott and Reinhardt 


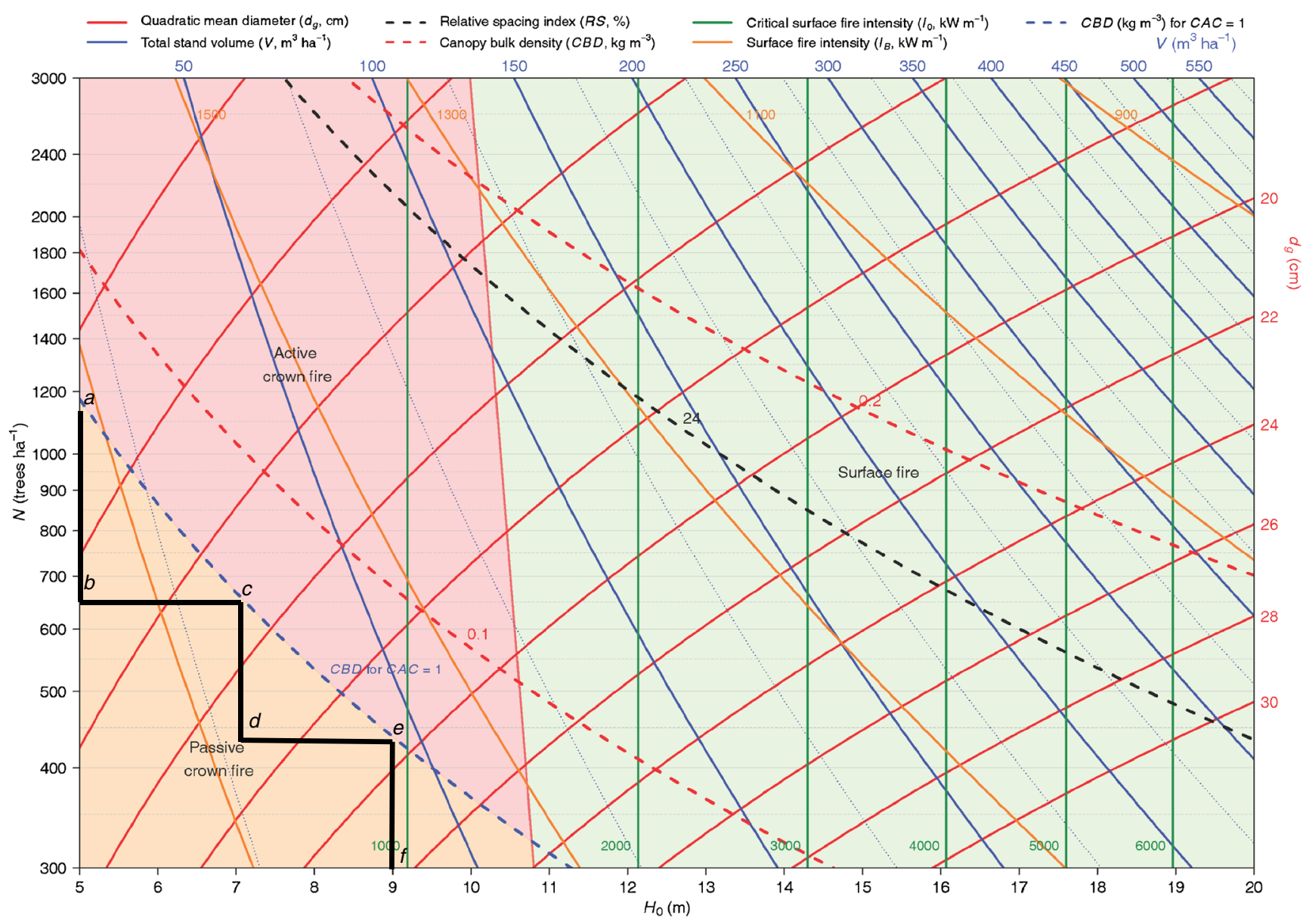

Fig. 3 DMD for maritime pine stands including isolines for $I_{\mathrm{B}}, I_{0}, C B D$ and $C B D$ where $\mathrm{CAC}=1$. Simulated conditions: $U_{10}=30 \mathrm{~km} \mathrm{~h}{ }^{-1}, M s=8 \%$, $F M C=100 \%, S=0^{\circ}$ and $F D$ and $S W a$ estimated from the 50th quantile regression models developed by Castedo-Dorado et al. (2012)

(2001) modelling system. Because the steady-state propagation of the crown fire phase is dependent on the surface fire for its inception and also for its propagation, such a situation is very unlikely to occur.

\subsection{Implications of the results}

According to the results shown in the DMDs, $H_{0}$ was the main predictor for classifying the wildfire type (surface or crown fire). Both stand density ( $N$, ultimately $G$ ) and, to a lesser extent, $H_{0}$ are useful for discriminating the type of crown fire (passive or active). Other European studies (e.g. Alvarez et al. 2012; Fernandes 2009; Fernández-Alonso et al. 2013) also used stand density and stand height to classify stand structures according to their potential to support different types of fire. The present findings are consistent with the results of these studies, although differences in species and burning conditions preclude detailed comparison.

Simulations by Fernández-Alonso et al. (2013) indicate low potential for active crown fires in pine stands (including maritime pine) under moderate to extreme burning conditions when $G<14.7 \mathrm{~m}^{2} \mathrm{ha}^{-1}$. According to Fernandes (2009), crowning potential in Portuguese maritime pine stands is expected to be very high in low stands (irrespectively of stand density), whereas tall stands ranked medium and null for closed and open stands, respectively. The present results are consistent with those obtained by this author (op. cit.), except for tall open structures. This discrepancy may be due to the fact that (according to the Portuguese NFI) the typical open maritime pine stand has less understory fuel load than the typical closed stand, while in NW Spain the opposite generally occurs (Castedo-Dorado et al. 2012).

Since stand structure affects crowning potential, thinning can alter the latter by affecting surface and crown fuel characteristics and within-stand wind speed. According to the results, the usefulness of stand density management is mainly limited to low (young) stands in order to prevent active crown fires (the most dangerous and intense type of wildfire). The "areas" defined within the DMDs (for the fuel and meteorological conditions simulated here) by the threshold $C B D 0.08$ $\mathrm{kg} \mathrm{m}^{-3}$ isolines are useful for designing thinning schedules. As an example, an initial stand defined by 1,200 stems per hectare and a dominant height of $5 \mathrm{~m}$ was assumed for intermediate (50th quantile regression models) shrub 


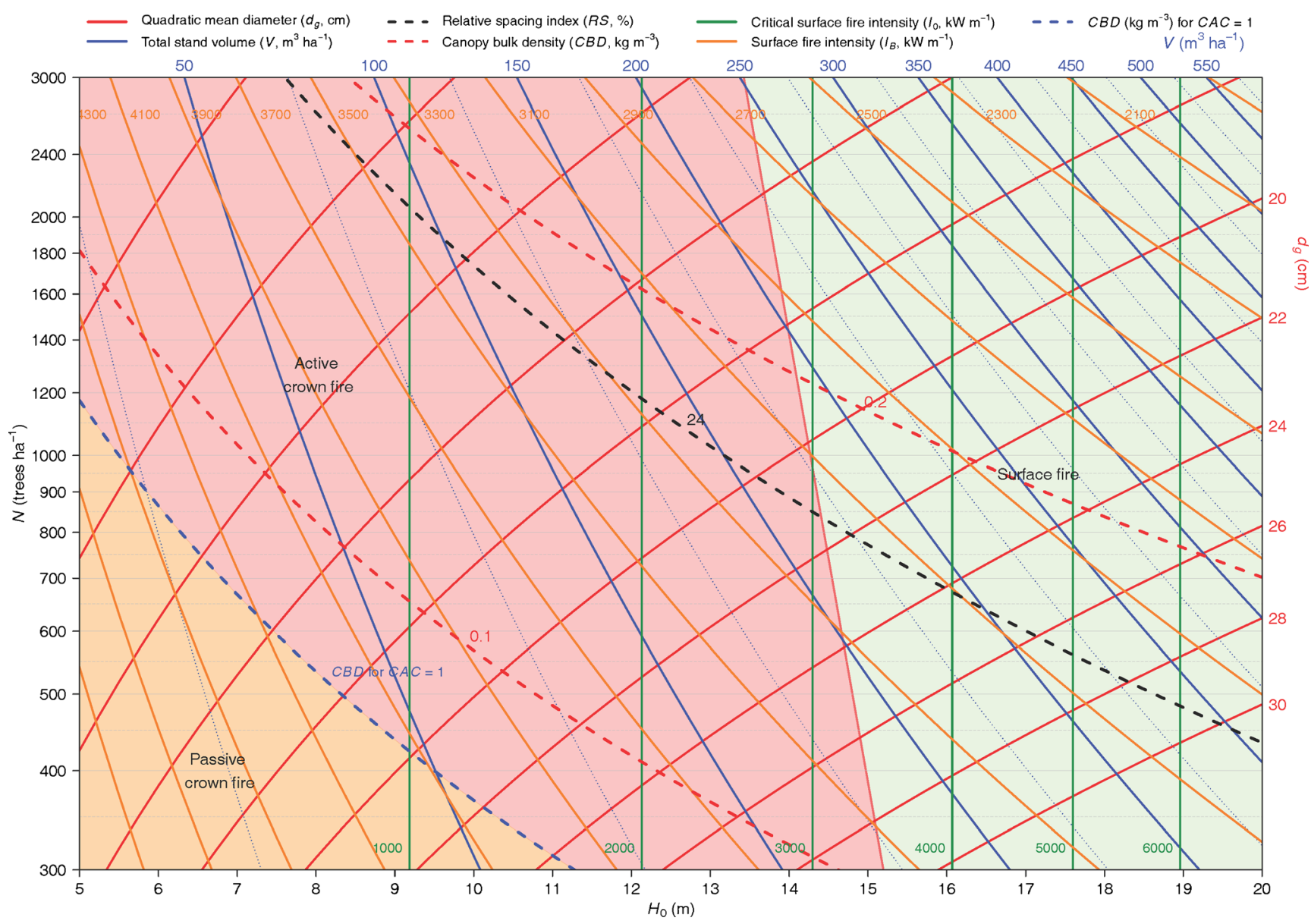

Fig. 4 DMD for maritime pine stands, including isolines for $I_{\mathrm{B}}, I_{0}, C B D$ and $C B D$ where $C A C=1$. Simulated conditions: $U_{10}=30 \mathrm{~km} \mathrm{~h}^{-1}, M s=$ $8 \%, F M C=100 \%, S=0^{\circ}$ and $F D$ and $S W a$ estimated from the 95 th and

development (Fig. 3). Considering a thinning interval based on a dominant height increment of $2 \mathrm{~m}$, the management schedule used to maintain the stand in the "passive crown fire area" will consist of three thinning operations (points $a$ to $f$ in Fig. 3). A first glance at the sequence of the three thinning operations clearly indicates that prevention of active crown fire in young stands implies low stand density (horizontal discontinuity in canopy fuels) through heavy thinning.

For adult (tall) stands, surface fire is expected irrespectively of stand density, making density management less important for avoiding crowning. This emphasizes the importance of promoting establishment of maritime pine plantations in high-quality sites to achieve a low-risk stand structure as quickly as possible.

In the DMDs, both $C B D$ and $I_{\mathrm{B}}$ respond to thinning from below (the most usual thinning option in $P$. pinaster stands) because they ultimately depend on $N$. On the contrary, critical fire intensity remains constant after silvicultural treatments because $I_{0}$ does not depends on $N$, although it is wellknown that thinning from below increases $C B H$ (Agee and Skinner 2005). Nevertheless, this simplification is irrelevant for decision making as the differences between both $I_{0}$ values are quite small. 97.5th quantile regression models, respectively, developed by CastedoDorado et al. (2012)

The maintenance of low $C B D$ was previously stated as an important management goal, at least in young stands (e.g. Keyes and O'Hara 2002). Maintaining CBD below the $0.08-\mathrm{kg} \mathrm{m}^{-3}$ threshold (or even below the nominal threshold of $0.1 \mathrm{~kg} \mathrm{~m}^{-3}$ ) involves density levels lower than those proposed for high dimension timber production ( $R S>24 \%$, see isolines in Figs. 3 and 4) (Balboa-Murias et al. 2006). Therefore, there is a clear trade-off between stand yield maximization and crown fire hazard minimization, at least in young stands (Fernandes and Rigolot 2007; Keyes and O'Hara 2002). Moreover, the objective of low stocking levels should also be balanced in view of other considerations. Individual tree growth is emphasized due to decreased competition, hence increasing log size. However, this may lead to the depreciation of wood physical properties, such as density and dimensional stability because of increased ring width and percentage of earlywood (e.g. Blakemore et al. 2010).

Because crown fire potential at stand level depends on the surface and canopy fuel complex, several other options (besides thinning) are available for proactive management of crown fire potential. Surface fuel management activities such as prescribed burning decrease potential surface fire intensity 
and can increase $C B H$ through fire-induced defoliation. Alternatively, pruning the lower branches can be carried out to increase the $C B H$. Broadscale (area-wide) fuel treatments are more effective, as fire behaviour is decreased over the entire stand, but practical and economical considerations recommend the establishment of crown-fire free zones as strategically located strips (Fernandes and Rigolot 2007).

The results of the present study, like any other based on fire modelling, are inherently limited by the simulation assumptions and process. The surface fire behaviour model of Fernandes et al. (2009) (and its recent modification; Fernandes 2014) does not consider slash from silvicultural operations (pruning or thinning) or from dead trees or branches. Moreover, simulations consider level terrain $\left(S=0^{\circ}\right)$, thereby eliminating the effect of slope on fire behaviour. Surface fire rate of spread approximately doubles for every $10^{\circ}$ increase in terrain slope (e.g. Fernandes et al. 2009). The corresponding increase in surface fire intensity facilitates crowning. Slope is also expected to increase crown fire rate of spread; however, it is not included as a variable in the model of Cruz et al. (2005) because of the nature of the experimental fire data used.

In addition, error propagation is a potential source of uncertainty and bias, although the percentage of variability explained by the equations used is generally higher than $80 \%$. Finally, the effects of the overstory on micrometeorological conditions and fuel characteristics were simplified. Stand structure affects both dead fine fuel moisture content and within-stand winds, but only the effect on within-stand wind speed was considered here. The effect on fuel moisture content was not accounted for because only a local comparison between an unthinned and a heavily thinned plot is available for maritime pine (Ruiz-González 2007), indicating a difference in fuel moisture content of about $2 \%$ on average, but not allowing generalization. Although open forest stands usually exhibit lower fuel moisture contents in comparison with closed stands, inter-study comparisons are inconclusive (e.g. Faiella and Bailey 2007), and the results cannot be generalized across forest canopy closure gradients, indicating that more research is needed.

Despite the aforementioned limitations, this study represents significant progress in the graphical assessment of crown fire potential, following early efforts (e.g. Dimitrakopoulos et al. 2007). The main novelty of the approach is that it allows consideration of how stand structure features affect crown fire potential over stand development. The inclusion of crown fire hazard variables in the DMD modelling framework had not previously been considered. López-Sánchez and RodríguezSoalleiro (2009) approached the problem by assessing crown fire hazard through $C B D$ isolines, but no information on variables related to surface to crown fire transition was provided.

Finally, it must be pointed out that DMDs are stand-level tools, and therefore, structure is only considered at this level.
Stand structure should also be addressed at larger scales because the landscape-level spatial arrangement of stands may influence the extent of crowning.

\section{Conclusions}

Graphical stand-level models (DMDs) were developed to provide stand variables for yield assessment, as well as a simple and rapid estimation of crown fire potential across the developmental stages of maritime pine stands. The isolines for assessing crown fire potential graphically represent variables related to both crown fire initiation (actual surface fire intensity and critical surface fire intensity) and spread (threshold $C B D$ for active crowning). These isolines distinguish "areas" of stand structures in the DMDs according to the expected type of fire, i.e. surface, passive crown or active crown fire.

Stand structure plays an important role in crown fire susceptibility in maritime pine stands. For the severe burning conditions simulated, crown fire potential is very high when stand dominant height is below $10.5 \mathrm{~m}(14 \mathrm{~m})$, and active crown fires are likely if $C B D$ is greater than $0.08 \mathrm{~kg} \mathrm{~m}^{-3}$. As variables related to crown fire potential are responsive to stand density, DMDs can be used to identify target stand structures and design density management schedules aimed at reducing the likelihood of crowning and thus create more fire-resistant stands.

Funding Funding for this research was provided by the Spanish Ministry of Science and Innovation, project no. AGL2008-02259/FOR.

\section{References}

Agee JK (1996) The influence of forest structure on fire behaviour. In: Cooper SL (ed) Proceedings of the 17th Annual forest vegetation management Conference, Shasta County Cooperative Extension, University of California, pp 52-68

Agee J, Skinner C (2005) Basic principles of forest fuel reduction treatments. For Ecol Manage 211:83-96

Albini FA, Baughman RG (1979) Estimating windspeeds for predicting wildland fire behavior. USDA Forest Service Intermountain Forest and Range Experiment Station Res Pap INT-221, 12 p

Alexander ME (1982) Calculating and interpreting forest fire intensities. Can J Bot 60:349-357

Alexander ME, Cruz MG (2006) Evaluating a model for predicting active crown fire rate of spread using wildfire observations. Can J Res 36: 3015-3028

Alexander ME, Cruz MG (2011) Crown fire dynamics in conifer forests. In: Synthesis of knowledge of extreme fire behavior: volume I for fire managers. USDA Forest Service Gen. Tech. Rep. PNW-GTR854, pp 107-142

Alvarez A, Gracia M, Retana J (2012) Fuel types and crown fire potential in Pinus halepensis forests. Eur J Res 131:463-474

Balboa-Murias MA, Rodríguez-Soalleiro R, Merino A, ÁlvarezGonzález JG (2006) Temporal variations and distribution of carbon 
stocks in aboveground biomass of radiata pine and maritime pine pure stands under different silvicultural alternatives. For Ecol Manage 237:29-38

Barrio-Anta M, Álvarez-González JG (2005) Development of a stand density management diagram for even-aged pedunculate oak stands and its use in designing thinning schedules. Forestry 78:209-216

Blakemore P, Cown D, Dumbrell I, McKinley R, Lyon A, Barr B, Northway R (2010) Western Australian Softwood Resource Evaluation: a survey of key characteristics of the Pinus radiata and Pinus pinaster resources in Western Australia with links to product performance of trees sampled from each resource, as determined by a processing. Forest \& Wood Products Australia Limited. Project No: PNC059-0809. http://www.fwpa.com.au/. Accessed 26 Jun 2013

Byram GM (1959) Combustion of forest fuels. In: Davis KP (ed) Forest fire: control and use. McGraw-Hill, New York, pp 90-123

Castedo-Dorado F, Crecente-Campo F, Álvarez-Álvarez P, Barrio-Anta M (2009) Development of a stand density management diagram for radiata pine stands including assessment of stand stability. Forestry $82: 1-16$

Castedo-Dorado F, Gómez-Vázquez I, Fernandes PM, Crecente-Campo F (2012) Shrub fuel characteristics estimated from overstory variables in NW Spain pine stands. For Ecol Manage 275:130-141

Cruz MG, Alexander ME, Wakimoto RH (2005) Development and testing of models for predicting crown fire rate of spread in conifer forest stands. Can J Res 35:1626-1639

Diéguez-Aranda U, Rojo A, Castedo-Dorado F, Álvarez JG, Barrio-Anta M, Crecente-Campo F, González JM, Pérez-Cruzado C, Rodríguez R, López-Sánchez CA, Balboa-Murias MA, Gorgoso JJ, Sánchez F (2009) Herramientas selvícolas para la gestión forestal sostenible en Galicia. Consellería do Medio Rural, Xunta de Galicia, Santiago de Compostela

Dimitrakopoulos AP, Mitsopoulos ID, Raptis DI (2007) Nomographs for predicting crown fire initiation in Aleppo pine (Pinus halepensis Mill.) forests. Eur J Res 126:555-561

Faiella SM, Bailey JD (2007) Fluctuations in fuel moisture across restoration treatments in semi-arid ponderosa pine forests of northern Arizona, USA. Int J Wildland Fire 16:119-127

Fernandes PM (2009) Combining forest structure data and fuel modeling to classify fire hazard in Portugal. Ann Sci 66:p415

Fernandes PM (2014) Upscaling the estimation of surface-fire rate of spread in maritime pine (Pinus pinaster Ait.) forest. iForest (in press)

Fernandes PM, Loureiro C (2013) Fine fuels consumption and $\mathrm{CO}_{2}$ emissions from surface fire experiments in maritime pine stands in northern Portugal. For Ecol Manage 291:344-356

Fernandes PM, Rigolot E (2007) The fire ecology and management of maritime pine (Pinus pinaster Ait.). For Ecol Manage 241:1-13

Fernandes PM, Loureiro CA, Botelho HS, Ferreira A, Fernandes M (2002) Avaliação indirecta da carga de combustível em pinhal bravo. Silva Lusit 10:73-90

Fernandes PM, Loureiro CA, Botelho HS (2004) Fire behaviour and severity in a maritime pine stand under different fuel conditions. Ann Sci 61:537-544

Fernandes PM, Botelho HS, Rego FC, Loureiro C (2009) Empirical modelling of surface fire behaviour in maritime pine stands. Int $\mathrm{J}$ Wildland Fire 18:698-710
Fernández-Alonso JM, Alberdi I, Álvarez-González JG, Vega JA, Cañellas I, Ruiz-González AD (2014) Canopy fuel characteristics in relation to crown fire potential in pine stands: analysis, modeling and classification. Eur J Res 132:363-377

Finney MA (2004) FARSITE: Fire Area Simulator-model development and evaluation. USDA Forest Service Rocky Mountain Research Station Research Paper RMRS-RP-4 Revised, $47 \mathrm{p}$

Gómez-Vázquez I, Crecente-Campo F, Diéguez-Aranda U, CastedoDorado F (2013) Modelling canopy fuel variables for Pinus pinaster Ait. and Pinus radiata D. Don in northwestern Spain. Ann Sci 70: $161-172$

Graham R, McCaffrey S, Jain T (tech eds) (2004) Science basis for changing forest structure to modify wildfire behavior and severity. USDA Forest Service Gen Tech Rep RMRS-GTR$120,43 \mathrm{p}$

Jiménez E, Vega JA, Ruiz-González AD, Guijarro M, Álvarez-González JG, Madrigal J, Cuiñas P, Hernando C, Fernández-Alonso JM (2013) Carbon emissions and vertical pattern of canopy fuel consumption in three Pinus pinaster Ait. active crown fires in Galicia (NW Spain). Ecol Eng 54:202-209

Keyes CR, O'Hara KL (2002) Quantifying stand targets for silvicultural prevention of crown fires. West J Appl 17:101-109

López-Sánchez C, Rodríguez-Soalleiro R (2009) A density management diagram including stand stability and crown fire risk for Pseudotsuga menziesii (Mirb.) Franco in Spain. Mount Res Dev 29:169-176

MARM (2011) Cuarto Inventario Forestal Nacional. Galicia. Dirección General del Medio Natural y Política Forestal. Parques Nacionales, Madrid

Newton PF (2012) A silvicultural decision-support algorithm for density regulation within peatland black spruce stands. Comput Electron Agric 80:115-125

Palheiro P, Fernandes P, Cruz M (2006) A fire behaviour-based fire danger classification for maritime pine stands: comparison of two approaches. In: Viegas DX (ed) Proceedings of the 5th International Conference on Forest Fire Research. Elsevier, Amsterdam

Pollet J, Omi PN (2002) Effect of thinning and prescribed burning on crown fire severity in ponderosa pine forests. Int J Wild Fire 11:1-10

R Development Core Team (2011) R: a language and environment for statistical computing. R Foundation for Statistical Computing. http:// www.R-project.org/. Accessed 21 Jan 2013

Ruiz-González AD (2007) Efecto de las claras sobre la humedad de los combustibles muertos en masas de pino. In: Abstracts of the 4th International Wildland Fire Conference, Wildfire 2007. Sevilla (Spain)

SAS Institute Inc (2009) SAS/ETS ${ }^{\circledR} 9.2$ user's guide. SAS Institute, Cary

Scott JH, Reinhardt ED (2001) Assessing crown fire potential by linking models of surface and crown fire behaviour. USDA Forest Service Res Pap RMRS-RP-29

Vacchiano G, Derose RJ, Shaw JD, Svoboda M, Motta R (2013) A density management diagram for Norway spruce in the temperate European montane region. Eur J For Res. doi:10.1007/ s10342-013-0694-1

Van Wagner CE (1977) Conditions for the start and spread of a crown fire. Can J Res 7:23-24 